\title{
Mental health of Filipino seafarers and its implications for seafarers' education
}

\author{
Sanley Salvacion Abila1 ${ }^{1}$, Iris Lavalle Acejo $^{2}$ \\ ${ }^{1}$ University of the Philippines Visayas, Iloilo City, Iloilo, Philippines \\ ${ }^{2}$ Seafarers International Research Centre, Cardiff University, Cardiff, United Kingdom
}

\begin{abstract}
This narrative review examines current academic literature on the mental health of Filipino seafarers working internationally, including the mental health effects of coronavirus disease 2019 (COVID-19). Framed within a rights-based approach, it aims to identify and analyse emerging themes on Filipino seafarers' mental health literature to understand what these studies potentially mean for the improvement of seafarers' education on mental health. Based on a broad selection criteria, 28 eligible papers demonstrate collectively three key findings: firstly, there is paucity in published research on seafarers' mental health; secondly, the majority of published studies are associated with a recent piracy crisis, where a significant number of mariners were attacked, taken as hostages, or killed; thirdly, three key areas emerged under which research on Filipino seafarers' mental health can be organized: the medical repatriation of seafarers, system of care for the mental health of seafarers including the diagnostic standards used, and seafarers' experiences and conceptions of mental health including the mental health effects of COVID-19.

Though the bulk of the current understanding of the mental health problems is associated with piracy, several risk factors for which the quality of quantitative and qualitative evidence are patchy. The few sources of primary data to date lack focus on mental health needs which makes it difficult to grasp the extent of the problem. Developing policies and programmes for the promotion of mental health through mental health education among seafarers is important for a couple of reasons. Seafaring remains a dangerous and socially isolating occupation where work-related accidents are likely and will be potentially traumatic to mariners. Research on occupational stressors is increasingly providing evidence of their contributions to poor mental health outcomes among seafarers. Thus, mental health education of seafarers in the context of their work is important for proactive training and development.
\end{abstract}

(Int Marit Health 2021; 72, 3: 183-192)

\section{Key words: mental health of Filipino seafarers, mental health education of seafarers, COVID-19 and mental health of seafarers}

\section{INTRODUCTION}

Research on mental health (herein after $\mathrm{MH}$ ) of merchant seafarers has recently gained increasing focus in terms of particularly framing $\mathrm{MH}$ as part of seafarers' well-being. To understand what these studies potentially mean for the improvement of seafarers' education on $\mathrm{MH}$, this paper reviews the academic literature on the $\mathrm{MH}$ of Filipino seafarers working aboard internationally flagged ships. A Filipino nationality-specific study on seafarers' $\mathrm{MH}$ is scarce in spite of their established presence in the maritime labour market sector since the 1970's. Studying this seafaring nationality offers a critical case in understanding seafarers' $\mathrm{MH}$ because it can offer insights about how nation-states and the global maritime industry can be seen promoting seafarers' $\mathrm{MH}$ through education. 
This paper is framed within a rights-based approach where human rights are viewed as rational and moral bases used in developing and implementing social interventions (e.g. education) aimed to produce public good (e.g. promoting good MH). This framing is attuned with World Health Organization's (WHO) definition of $\mathrm{MH}$ as "a state of well-being in which the individual realises his or her own abilities, can cope with the normal stresses of life, can work productively and fruitfully, and is able to make a contribution to his or her community" [1]. Though WHO's definition is not without criticisms [2], it remains influential as nation-states such as the Philippines adopt it in its $\mathrm{MH}$ law, the 2018 Philippine Mental Health Act [3]. In the $\mathrm{MH}$ law, the promotion of $\mathrm{MH}$ of Filipinos is valued as part of their basic rights. In effect, various organizations such as maritime schools and maritime employers are mandated by law to formulate $\mathrm{MH}$ policies and programmes for students and workers, respectively, as part of both promoting and supporting the $\mathrm{MH}$ of Filipinos [3]. These legal developments are crucial as seafaring remains one of the most attractive employment options for young Filipinos but remains as one of the most dangerous occupations $[4,5]$ with growing evidence of poor $\mathrm{MH}$ outcomes among seafarers.

Current research on seafarers' $\mathrm{MH}$ revolves around two related aspects [6, 7]. Firstly, research compare seafarers' $\mathrm{MH}$ with land-based workers, primarily comparing evidence on clinical psychological ill health such as depression, anxiety, and suicide rates [8]. Secondly, research tend to examine risk factors (or occupational stressors) related to the working and living environment aboard vessels which contribute to poor $\mathrm{MH}$ [9]. These include long-term separation from home, fatigue and work intensification [10, 11], multinational crewing, social isolation [12], ill-treatment, poor life-work balance, job insecurity, criminalization of seafaring activities, working in constrained space, bullying, piracy [13-15], lack of shore leave, short port stay, HIV/AIDS [16] or in general terms psychosocial and psychophysical stress [17-20].

Merchant mariners are collectively a global workforce estimated at around 1,647,500 in 2015 where Filipino seafarers constitute at least $20 \%$ of this global population [21]. In a report, the Philippines is the top supplier of ratings and ranks second in supplying officers to the international labour market [21]. Financially, deployment of seafarers translates to substantial remittances sent to the Philippines where in 2019 remittances amounted to US\$6.53 billion, after sending US\$6.13 billion in 2018 [22].

\section{NARRATIVE REVIEW AND LIMITATIONS OF THE STUDY}

For this narrative review, the focus is to construct a discussion on the state of $\mathrm{MH}$ research on Filipino sea- farers working internationally. To do this, six databases were searched (EBSCOhost, Google Scholar, Medline, and ProQuest which has 3 databases - Coronavirus research database, ProQuest One Academic and Publicly Available Content Database) where studies from 2000 to 2020 were considered. To augment academic publications, this paper also looked into the grey literature which includes research studies published outside the typical academic and commercial publishing networks (Examples of these are industry papers, reports of charities, government reports, seafarers' union reports, etc.) in order to examine what policies, standards, strategies, interventions and the like were dedicated to protecting or promoting the $\mathrm{MH}$ of seafarers.

Two independent reviewers searched for eligible materials with the following inclusion criteria: the date of publication, key search terms, the language (English) of the manuscripts, and inclusion of Filipino seafarers in the study sample. A 21-year period (i.e. 2000-2020) was used in order to cover the most recent research on the $\mathrm{MH}$ of Filipino seafarers. For the key search terms, the following were used: "Filipino seafarers and mental health", "mental well-being/welfare of Filipino seafarers", "psychological health of Filipino seafarers", "mental stress among Filipino seafarers", "psychological stress among Filipino seafarers", "depression among Filipino seafarers", "suicide among Filipino seafarers", "mental anxiety and Filipino seafarers", "social isolation among Filipino seafarers", and "maritime piracy and Filipino seafarers". Based on the various search terms and other inclusion criteria, the two reviewers assessed multiple studies as the initial hits were too many ranging from 55 to 13,400 but with a significant number of these deemed ineligible. Abstracts and titles of top hits were assessed against the inclusion criteria, which eventually was narrowed down to 28 eligible materials where 17 are academic publications and 11 are either reports of organizations or conference presentations. As a limitation of this paper, the studies included in this paper were not based on a highly systematic criteria-based strategy but primarily for their thematic relevance based on the broad inclusion and exclusion criteria.

\section{FINDINGS AND ANALYSIS}

This review found 28 eligible studies based on the broad criteria set above (Table 1). In general terms, the findings from these studies are:

1. There is paucity in academically published research on the $\mathrm{MH}$ of seafarers in spite of the established presence of Filipinos in the international seafaring labour market.

2. The majority of published materials began after the peak of maritime piracy crisis between 2009 to 2012, where a significant number of Filipino mariners were attacked, taken as hostages, or killed in hostage situations. 


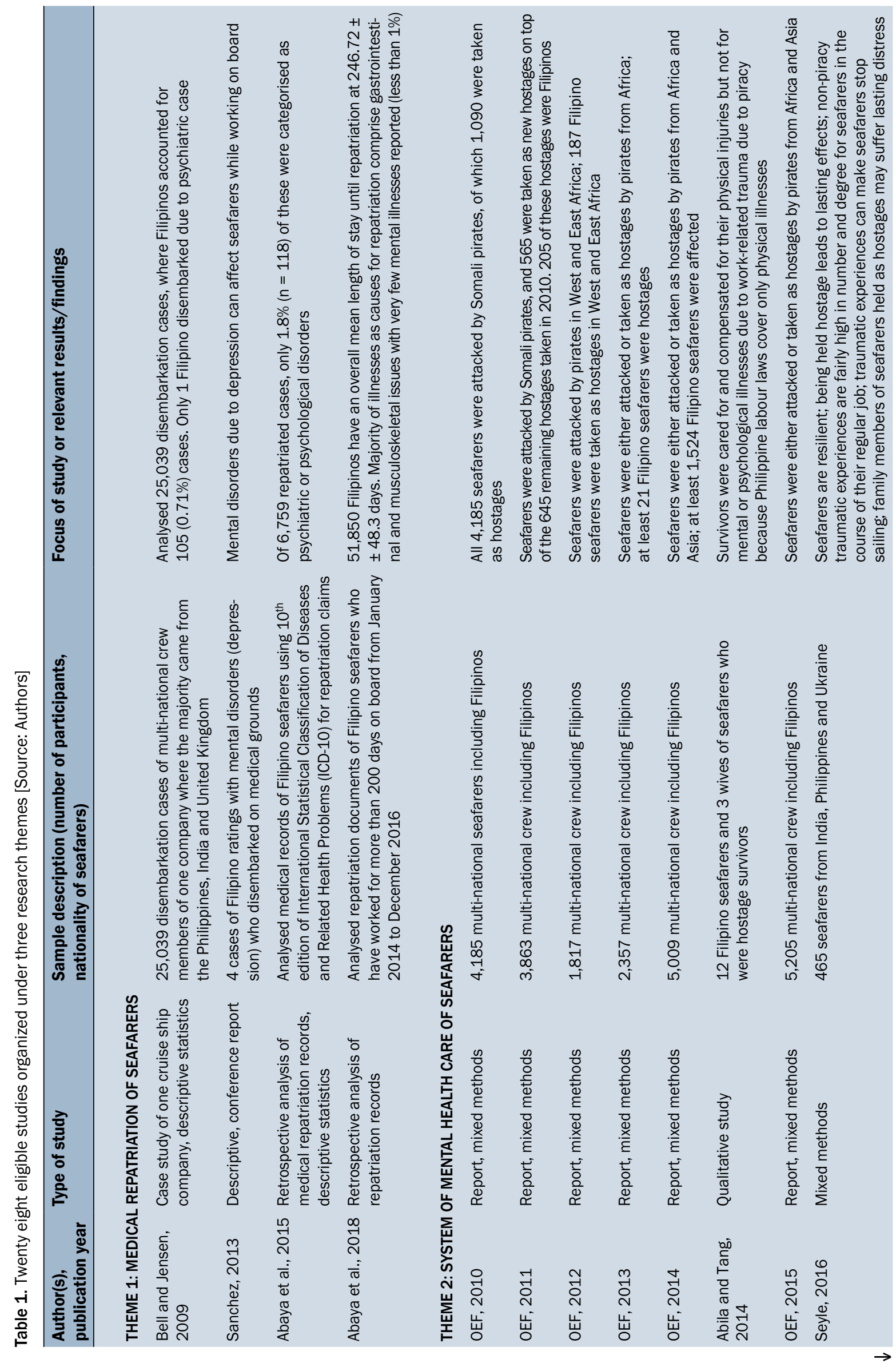




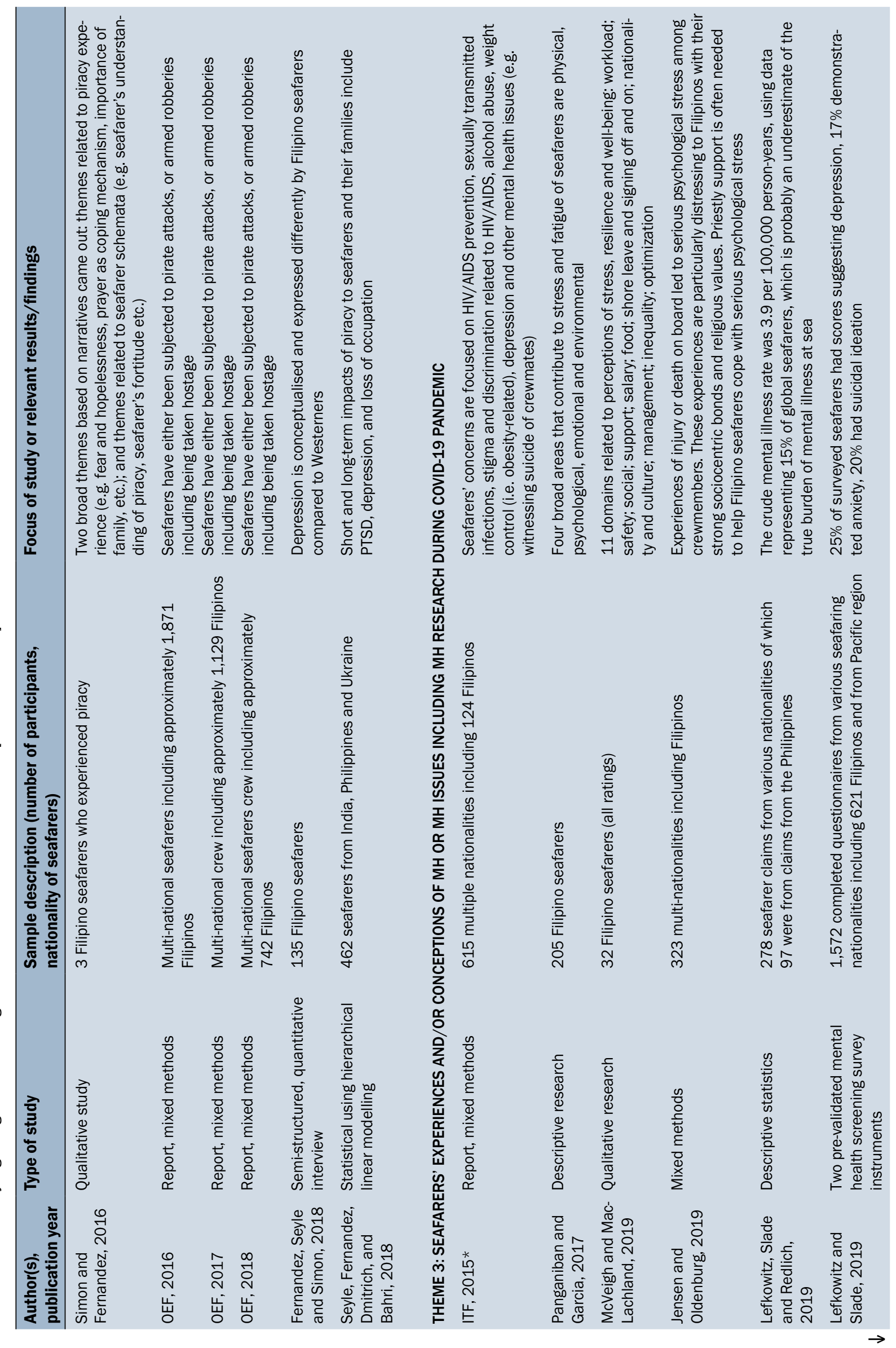




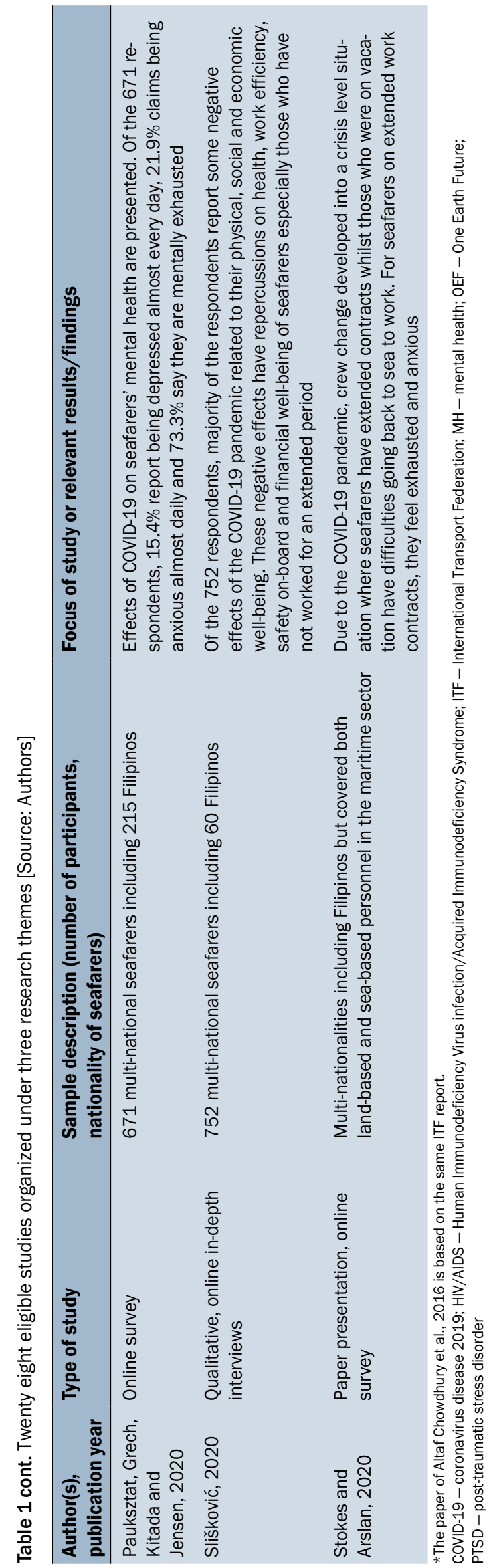

3. Of the materials considered, three themes illustrate major areas under which research on seafarers' $\mathrm{MH}$ are organized: medical repatriation of seafarers, system of care for the $\mathrm{MH}$ of seafarers including diagnostic standards, and seafarers' experiences and conceptions of $\mathrm{MH}$ including studies examining the effects of the on-going pandemic caused by the coronavirus disease 2019 (COVID-19) on seafarers' MH. These themes are discussed below.

\section{KEY THEMES ON RESEARCH ON THE MENTAL HEALTH OF FILIPINO MARINERS}

The first thematic finding focuses on the medical repatriation of seafarers. Repatriation of seafarers is the transport of the seafarer from his/her home address to the port of call of a vessel to be boarded. Under Philippine law, the repatriation of seafarers is the responsibility of employers including medical repatriation, which is the disembarkation of a seafarer on medical grounds [23]. Medical repatriation of Filipinos remains surprisingly understudied [24]. In Abaya et al.'s study [24], between January 2010 and December 2014 there were 6,759 repatriated cases based on medical reasons. Of these cases, $1.8 \%(n=118)$ were categorised as psychiatric disorders (i.e. anxiety, depression, psychosis/schizophrenia or bipolar disorder) [24]. While 4 cases of disembarkation of Filipino ratings with mental illnesses were reported in a $2013 \mathrm{MH}$ conference [25]. The same very low reporting of mental illnesses can be seen in Bell and Jensen's [26] work where of the 25,039 cases of disembarkation due to various medical reasons, Filipinos accounted for less than $1 \%$ of these cases (i.e. 105) but only one psychiatric case [26]. Lastly, 1 study analysed repatriation documents of 51,850 Filipinos who have worked for more than 200 days on board from January 2014 to December 2016. They found less than $1 \%$ were repatriated due to mental ill-health [27].

The second theme centres on the system of mental health care of seafarers, including diagnostic standards used. Most of these studies under this theme were outputs related to the maritime piracy research of One Earth Future Foundation, a non-governmental organization. These and similar studies came out at the height of the maritime piracy crisis particularly from 2009 to 2012, where a significant number of seafarers including Filipinos were taken as hostages and a number were killed in hostage situations. The foundation produced a series of annual reports from 2010 to 2018 focusing on the state of maritime piracy, where approximately more than 6,000 Filipinos have been subjected to pirate attacks and/or armed robberies including being taken as hostages by pirates from 2009 to 2019 [28-36]. It is also reported that the families of seafarers especially those taken as hostages suffer as much 
as the seafarers, including being psychologically impacted by the captivity of seafarers [13]. In the last decade, the maritime industry was pushed to act because of economic impact and human suffering caused by piracy crimes could not be ignored. In effect, in terms of research this crisis led to an acute focus on the psychological impacts of piracy on seafarers.

In Abila and Tang [37], the authors presented qualitative evidence on the physical and psychological abuses that Filipino seafarers experienced as hostages of pirates, and the potential psychological effects of these abuses. In Fernandez et al. [38], the authors provided limited evidence that depression is conceptualised and expressed differently by Filipino seafarers compared to Westerners. In their study the sample of seafarers' conceptualisation of depression has certain distinctions from a Western sample. The authors applied the United States' Centre for Epidemiological Studies - Depression (CES-D) scale to Filipino seafarers in order to identify the appropriate factor structure of CES-D for 135 seafarers. CES-D scale was developed in the United States and it uses a four-factor structure [39]. The authors found that a three-factor structure is appropriate for the surveyed population instead of the four-factor structure used in other studies. The seafarers' factor structure appears to collapse depressive affect and somatic factors found in other studies, while including a specific factor of social-focused symptoms of depression [38]. In other words, when compared to the established factor structure of CES-D the sample of Filipino seafarers' conceptualisation of depression has certain distinctions from a Western sample.

Fernandez et al. [38] argued that this conceptualization of depression has implications for the clinical diagnosis of depression and depressive symptoms among Filipinos. They argued that the communication of physical distress, particularly when Filipinos do not differentiate between emotions or feelings and bodily discomfort might imply that these expressions may have significance when assessing their mental or psychological health. As noteworthy, the authors pointed out that among the respondents feeling disconnected from others is an important expression of their conceptualisation of depression [38]. It appears that depression is viewed as interpersonal because their study has shown that Filipinos believe that the interpersonal integrates physical with psychological well-being where one's self-conception includes the other. In effect, it is suggested that clinical diagnostics of depression of Filipinos should afford the time and space for the examination of the client's interpersonal context.

The third theme focuses on the experiences and conceptions of Filipino mariners of their $\mathrm{MH}$ including the relationship of MH to their well-being. Research which falls under this theme are the report of the International Transport Federation (ITF) [40], Altaf Chowdhury et al. [16], Panganiban and Garcia [41], McVeigh and MacLachland [42], Jensen and Oldenburg [43], Simon and Fernandez [44], Lefkowitz and Slade [45] and Lefkowitz et al. [46].

Using the broader concept of seafarers' well-being, ITF's [40] survey showed that among seafarers, Filipinos included, HIV/AIDS remains a pressing concern together with other MH concerns (e.g. depression, alcohol use) and related health concerns such as nutrition and obesity. The work of Altaf Chowdhury et al. [16] is based on the same ITF Report [40] thus these two have similar key MH findings.

In Panganiban and Garcia [41], 205 Filipinos were surveyed on factors that contribute to stress and fatigue. In this study, four broad areas are presented to contribute to stress and fatigue of seafarers, which are the physical, psychological, emotional and environmental aspects of seafaring.

In the study of McVeigh and MacLachland [42], the authors examined Filipino ratings' perceptions and experiences of stress, resilience and well-being in relation to 11 domains (i.e. workload, safety, social, support, salary, shore leave, signing off and on, nationality and culture, management, inequality, and optimization). Stress is reported to be a very common and day-to-day experience of seafarers that is known to contribute to poor MH. This finding is not novel but echoes a commonly held view on seafarers' health research where stress is considered not only a perennial problem but a day-to-day reality.

Jensen and Oldenburg [43] examined serious psychological stress among crewmembers of different nationalities due to experiences of serious injuries or death of crewmates on board. The study argues that the experiences of serious injuries or death of crewmates are particularly distressing to the Filipino crew with their strong sociocentric bonds and religious (i.e. Christian) values. Due to the dominance of Roman Catholicism in the Philippines, chaplain or priestly support is often needed to help Filipino seafarers cope with serious psychological stresses [47].

The work of Simon and Fernandez [44] explored meanings of experiencing piracy based on the accounts of 3 Filipino seafarers. This qualitative phenomenological paper found out that seafarers ascribed 4 clusters of meanings to their piracy experiences, which are fear and hopelessness, holding on to protocol, prayer as an automatic coping response, and the importance of the family, where the thematic finding of fear and hopelessness appears to be most salient among the participants [44].

In Lefkowitz and Slade [45], 1,572 seafarers were surveyed from various seafaring nationalities including 621 Filipinos. Of these, $25 \%$ had scores suggesting depression, $17 \%$ demonstrated anxiety, and $20 \%$ had suicidal ideation.

The work of Lefkowitz et al. [46] analysed 278 seafarer claims from various nationalities including 97 Filipinos. Using data representing $15 \%$ of global seafarers, a crude 
mental illness rate was calculated at 3.9 per 100,000 person-years, which is probably an underestimate of the true burden of mental illness at sea.

Lastly, a significant number of seafarers including Filipinos are already facing negative consequences to their $\mathrm{MH}$ due to the on-going pandemic. These negative effects include coping with extended stay on board ships due to difficulties in crew change owing to national travel restrictions and having very few opportunities for shore leave when in ports. Four studies demonstrate various effects of COVID-19 on seafarers' MH including anxiety, mental exhaustion even depression due to extended contracts working aboard vessels [48-51]. Of the 671 respondents in the study of Pauksztat et al. [48], 32\% are Filipinos. Among the respondents, $15.4 \%$ expressed being depressed almost daily, $21.9 \%$ claimed being anxious almost daily and $73.3 \%$ said they are mentally exhausted [48]. In the work of Slišković [49], 7.7\% of the 752 respondents are Filipinos. Majority of the respondents report some negative effects of the pandemic related to their physical, social and economic well-being. These negative effects have repercussions on health, work efficiency, safety on-board and financial well-being of seafarers especially those who have not worked for an extended period [49].

In summary, the available evidence describing Filipino seafarers' MH was presented in relation to three issues: mental illnesses as bases of seafarers' repatriation, system of care for seafarers' MH, and experiences or conceptions of seafarers of MH. However, each of these areas were based on studies which offered very limited evidence, and thus, it is very hard to come up with robust generalisations or a broad picture of the MH of Filipino seafarers. For example, Abaya et al.'s [24] medical repatriation data of Filipino seafarers based on aggregate level data of Manila-based manning agencies makes it difficult to gauge whether the pattern widely represents the norm. The publicly available list of manning agencies is incomplete in terms of several indicators such as organizational size and number of ships or seafarers it handles for a certain reference year. As the available data from various maritime bodies and administrations are not well organized, it has become difficult to construct even the crudest measure of repatriation.

A couple of notable gaps in the existing literature pertains to the lack of systematic recording and reporting of suicide cases for which the repatriation data cannot provide a clear insight as a proxy indicator, and detailed discussions of MH concerns of women seafarers (e.g. sexual harassment and $\mathrm{MH}$ ). The disclosures of severe $\mathrm{MH}$-related problems such as suicide or sexual harassment are stigmatising experiences for seafarers who become vulnerable to unfair labour practices. An implicit assumption of the shipboard environment as the natural setting to conduct $\mathrm{MH}$ research limits the current understanding of the extent of $\mathrm{MH}$ problems for Filipino seafarers because of the practical problems in conducting extensive $\mathrm{MH}$ research aboard vessels. Nevertheless, the existing body of $\mathrm{MH}$ research taken collectively as well as the enactment of the Philippine $\mathrm{MH}$ law are providing an urgency to advocate for the inclusion of $\mathrm{MH}$ in the education of Filipino seafarers and among key stakeholders in the maritime sector, particularly the government, employers, healthcare professionals, chaplains, and families of seafarers. Seafarers and aspiring seafarers must be provided with evidence-based data on seafarers' MH to promote, protect and support relevant MH educational initiatives.

\section{DISCUSSION AND CONCLUSIONS}

Despite the emerging evidence highlighted above, the scant research is a major problem in itself. The bulk of the current understanding of the $\mathrm{MH}$ problems of Filipino seafarers relates to distress arising from piracy attack. Yet, $\mathrm{MH}$ problems have several facets (i.e. risk factors on board) for which the quality of evidence is patchy both in terms of methodology and treatment design. The few sources of primary data on Filipino seafarers to date lack focus on mental health needs which makes it difficult to grasp the extent of the problem. The situation regarding seafarers' disclosure of $\mathrm{MH}$ as well as disclosures of ship operators or companies suffers from inconsistent reporting and a lack of a mandatory centralised database offers little help in understanding repatriation and suicide rates.

The qualitative work alongside quantitative methods under the system of $\mathrm{MH}$ care highlighted areas crucial for understanding $\mathrm{MH}$ needs. However, the qualitative studies are very few but some of these demonstrate that cultural conceptualisation of $\mathrm{MH}$ (e.g. depression) has implications for the clinical diagnosis of $\mathrm{MH}$ problems [38]. Hence, qualitative approaches such as phenomenological research on $\mathrm{MH}$ [44] are full of potentials in better understanding $\mathrm{MH}$ of seafarers because they are often times grounded on the subjective and cultural experiences and views of seafarers.

The evidence presented reflects a mosaic of necessary interventions from different organizations. The lack of data, however, on how work levels in terms of task, individuals, team and organizational culture and its complex interaction with $\mathrm{MH}$ needs make it difficult to identify how these link to $\mathrm{MH}$ distress. Unmet data needs at various levels: firms, maritime authorities and other agencies can provide the necessary direction for both qualitative and quantitative inquiries on seafarers' MH conception, among others. The kind of social support and adaptive coping mechanisms for seafarers can highlight the quality of care required including how it can be best established and sustained as well as in what form of health services. The lack of foresight in 
planning and policies aimed at primary prevention of $\mathrm{MH}$ hamper appropriate interventions of emerging concerns.

Developing policies and programmes for the $\mathrm{MH}$ education of seafarers and other key maritime stakeholders are, therefore, crucial for two broad reasons. Firstly, seafaring remains a dangerous and socially isolating occupation where work-related accidents will likely continue and will be potentially traumatic to crewmembers. Secondly, research on occupational stressors of seafaring is increasingly providing evidence of their contributions to poor MH outcomes. Given this scenario, governments like in the Philippines and key maritime stakeholders appear to be duty bound to protect and support $\mathrm{MH}$ initiatives especially in educating seafarers.

Ideally, maritime students and seafarers will be educated in the basics of $\mathrm{MH}$ in the context of their work, so that they can be trained to manage not only their $\mathrm{MH}$ but their health in general. The biomedical model of $\mathrm{MH}$ suggests that psychological problems are diseases of the brain [52]. This model has dominated the diagnosis and treatment of $\mathrm{MH}$ because it is the model which is the basis of mainstream practice of the mental healthcare of seafarers. Developing $\mathrm{MH}$ educational policies and programmes based on this model, which the literature refers to as psychoeducation is arguably necessary for seafarers and their families not only after surviving traumatic episodes but also in daily life routines. Psychoeducation means providing seafarers with basic information on probable impact of traumatic experiences, coping strategies and other fundamental techniques that aid recovery from trauma. It involves identifying the types of symptoms which may require additional support to every survivor of traumatic experiences along with targeted support and interventions designed to help seafarers with more specific distress.

The biopsychosocial model of $\mathrm{MH}$ is a healthcare model where clinicians or caregivers offer a holistic approach to care where the biological, psychological and socio-cultural dimensions of mental illnesses are addressed simultaneously by professional healthcare workers [53]. This model attempts to bring the subjective experiences of illness of the clients into clinical practice hence this model gives voice and power to the client and not just to the professionals [53]. A biopsychosocial model is advocated by port chaplains because they argue that seafarers come from different cultures and religions where their concepts of relief from distress, for example, can at times be influenced by their religions [47]. Thus, aside from the dominant biomedical model of $\mathrm{MH}$, other models such as the biopsychosocial model should also be part of the education of seafarers. To recap, an $\mathrm{MH}$ education programme for seafarers should be informed by basic and different models of mental healthcare, which seafarers can actually use during their seafaring careers.
A particular gap in $\mathrm{MH}$ research on Filipino seafarers for future researchers to consider is the need of a culture-based conceptualisation of mental illnesses. It can be recalled that researchers suggested an appropriate culture-based psychological diagnostics and interventions for Filipino seafarers [38]. For health care providers, the potential changes in psychological diagnostics of Filipino seafarers suggested here must be incorporated in their clinical education and training as health care professionals and port chaplains are often times the first responders to traumatised seafarers. Lastly, future research should prioritise collecting robust data on suicide among Filipino seafarers because its absence makes it very conspicuous and without it a broad and clear picture of Filipino seafarers' mental health is incomplete.

\section{Conflict of interest: None declared}

\section{REFERENCES}

1. World Health Organization. Promoting mental health: concepts, emerging evidence, practice: a report of the World Health Organization, Department of Mental Health and Substance Abuse in collaboration with the Victorian Health Promotion Foundation and the University of Melbourne. World Health Organization. 2005.

2. Galderisi S, Heinz A, Kastrup M, et al. Toward a new definition of mental health. World Psychiatry. 2015; 14(2): 231-233, doi: 10.1002/wps.20231, indexed in Pubmed: 26043341.

3. Republic Act 11036 or the Mental Health Act of the Philippines of 2018. Congress of the Republic of the Philippines.

4. Roberts SE, Nielsen D, Kotłowski A, et al. Fatal accidents and injuries among merchant seafarers worldwide. Occup Med (Lond). 2014; 64(4): 259-266, doi: 10.1093/occmed/kqu017, indexed in Pubmed: 24671028.

5. Walters D, Bailey N. Lives in peril: Profit or safety in the global maritime industry? Springer, Hampshire, UK 2013.

6. Iversen RTB. The mental health of seafarers. Int Marit Health. 2012; 63(2): 78-89, indexed in Pubmed: 22972547.

7. Sampson H, Ellis N. Seafarers' mental health and wellbeing. IOSH 2019.

8. Mellbye A, Carter T. Seafarers' depression and suicide. Int Marit Health. 2017; 68(2): 108-114, doi: 10.5603/IMH.2017.0020, indexed in Pubmed: 28660614.

9. Slišković A, Penezić Z. Occupational stressors, risks and health in the seafaring population. Rev Psychology. 2016; 22(1-2): 29-39, doi: 10.21465/rp0022.0004.

10. Dohrmann SB, Leppin A. Determinants of seafarers' fatigue: a systematic review and quality assessment. Int Arch Occup Environ Health. 2017; 90(1): 13-37, doi: 10.1007/s00420-016-1174-y, indexed in Pubmed: 27804037.

11. Hystad SW, Eid J. Sleep and fatigue among seafarers: the role of environmental stressors, duration at sea and psychological capital. Saf Health Work. 2016; 7(4): 363-371, doi: 10.1016/j. shaw.2016.05.006, indexed in Pubmed: 27924241.

12. Sampson $H$, Thomas $M$. The social isolation of seafarers: causes, effects, and remedies. Int Marit Health. 2003; 54(1-4): 58-67, indexed in Pubmed: 14974778.

13. Seyle D, Fernandez K, Dimitrevich A, et al. The long-term impact of maritime piracy on seafarers' behavioral health and work decisions. Marine Policy. 2018; 87: 23-28, doi: 10.1016/j.marpol.2017.10.009. 
14. Seyle DC, Bahri C, Brandt K. After the release: The long-term behavioral impact of piracy on seafarers and families. One Earth Future Foundation, Broomfield, CO 2016.

15. Ziello AR, Degli Angioli R, Fasanaro AM, et al. Psychological consequences in victims of maritime piracy: the Italian experience. Int Marit Health. 2013; 64(3): 136-141, indexed in Pubmed: 24072540.

16. Altaf Chowdhury SA, Smith J, Trowsdale S, et al. HIV/AIDS, health and wellbeing study among International Transport Workers' Federation (ITF) seafarer affiliates. Int Marit Health. 2016; 67(1): 42-50, doi: 10.5603/IMH.2016.0009, indexed in Pubmed: 27029929.

17. Carter T. Working at sea and psychosocial health problems Report of an International Maritime Health Association Workshop. Travel Med Infect Dis. 2005; 3(2): 61-65, doi: 10.1016/j.tmaid.2004.09.005, indexed in Pubmed: 17292007.

18. Oldenburg M, Jensen HJ. Stress and strain among merchant seafarers differs across the three voyage episodes of port stay, river passage and sea passage. PLoS One. 2019; 14(6): e0217904, doi: 10.1371/journal.pone.0217904, indexed in Pubmed: 31163071.

19. Carotenuto A, Fasanaro AM, Molino I, et al. The Psychological General Well-Being Index (PGWBI) for assessing stress of seafarers on board merchant ships. Int Marit Health. 2013; 64(4): 215-220, doi: 10.5603/imh.2013.0007, indexed in Pubmed: 24408143.

20. Carotenuto A, Molino I, Fasanaro AM, et al. Psychological stress in seafarers: a review. Int Marit Health. 2012; 63(4): 188-194, indexed in Pubmed: 24595974.

21. Baltic and International Maritime Council (BIMCO) and International Chamber of Shipping (ICS). The Global Demand and Supply of Seafarers in 2015. The Baltic and International Maritime Council (BIMCO) and International Chamber of Shipping (ICS), 2015.

22. Bangko Sentral ng Pilipinas. Overseas Filipinos' Cash Remittances. 2019.

23. Philippine Overseas Employment Administration (POEA). Memorandum Circular No. 14, Series of 2018. Guidelines in the Repatriation of Overseas Filipino Workers (OFWs) and Seafarers.

24. Abaya AR, Roldan S, Ongchangco JC, et al. Repatriation rates in Filipino seafarers: a five-year study of 6,759 cases. Int Marit Health. 2015; 66(4): 189-195, doi: 10.5603/IMH.2015.0038, indexed in Pubmed: 26726888.

25. Sanchez M. Emerging Mental cases. In: Jeżewska M, Iversen RT, Leszczyńska I. MENHOB - Mental Health on Board. In 12th International Symposium on Maritime Health; 2013 Jun 6. Brest, France. Int Marit Health. 2013; 64(3): 168-174.

26. Bell SS, Jensen OC. An analysis of the diagnoses resulting in repatriation of seafarers of different nationalities working on board cruise ships, to inform pre-embarkation medical examination. Med Marit. 2009; 9(1): 32-43.

27. Abaya A, Rivera J, Roldan S, et al. Does long-term length of stay on board affect the repatriation rates of seafarers? Int Marit Health. 2018; 69(3): 157-162, doi: 10.5603/imh.2018.0025.

28. Hurlburt K. The Human Cost of Somali Piracy. One Earth Future Foundation, Broomfield, CO, USA; 2011. http://oceansbeyondpiracy.org/sites/default/files/human_cost_of_somali_piracy.pdf (Last accessed 11 January 2021).

29. One Earth Future. The Human Cost of Somali Piracy 2011. One Earth Future Foundation, Broomfield, CO, USA; 2012. http://oceansbeyondpiracy.org/sites/default/files/economic_cost_of_piracy_2011. pdf (Last accessed 11 January 2021).

30. Hurlburt K. The Human Cost of Somali Piracy 2012. One Earth Future Foundation, Broomfield, CO, USA; 2013. doi: 10.18289/ OBP.2013.001. https://oefresearch.org/sites/default/files/documents/publications/hcop2012forweb_6.pdf (Last accessed 11 January 2021).
31. Oceans Beyond Piracy. The State of Maritime Piracy 2013. One Earth Future Foundation, Broomfield, CO, USA; 2014. http://oceansbeyondpiracy.org/sites/default/files/attachments/SoP2013-Digital_0. pdf (Last accessed 11 January 2021).

32. Oceans Beyond Piracy. The State of Maritime Piracy 2014: Assessing the Economic and Human Cost. One Earth Future Foundation, Broomfield, CO, USA; 2015. DOI: 10.18289/ OBP.2015.001. http://oceansbeyondpiracy.org/sites/default/ files/attachments/StateofMaritimePiracy2014.pdf (Last accessed 11 January 2021).

33. One Earth Future Foundation. The State of Maritime Piracy 2015: Assessing the Economic and Human Cost. One Earth Future Foundation, Broomfield, CO, USA; 2016. http://oceansbeyondpiracy. org/sites/default/files/State_of_Maritime_Piracy_2015.pdf (Last accessed 11 January 2021).

34. One Earth Future Foundation. The State of Maritime Piracy 2016. One Earth Future Foundation, Broomfield, CO, USA; 2017. http:// oceansbeyondpiracy.org/sites/default/files/one_earth_future_state_of_piracy_report_2017.pdf (Last accessed 11 January 2021).

35. One Earth Future Foundation. The State of Maritime Piracy 2018. One Earth Future Foundation, Broomfield, CO, USA; 2018. https:// www.stableseas.org/sites/default/files/stateofpiracy2018_0.pdf (Last accessed 11 January 2021).

36. One Earth Future Foundation. The State of Maritime Piracy 2019. One Earth Future Foundation, Broomfield, CO, USA; 2020. https:// www.stableseas.org/sites/default/files/stateofpiracy2019.pdf (Last accessed 11 January 2021).

37. Abila S, Tang L. Trauma, post-trauma, and support in the shipping industry: The experience of Filipino seafarers after pirate attacks. Marine Policy. 2014; 46: 132-136, doi: 10.1016/j. marpol.2014.01.012.

38. Fernandez K, Seyle D, Simon E. The conceptualization of depression among Filipino seafarers. J Pacific Rim Psychology. 2018; 12: e23, doi: 10.1017/prp.2018.12.

39. Radloff LS. The CES-D scale: A self-report depression scale for research in the general population. App Psych Measurement. 1977; 1(3): 385-401, doi: 10.1177/014662167700100306.

40. Maritime IT. A Broader Vision of Seafarer Wellbeing: Survey of ITF Maritime Affiliates on HIV/Aids, Health and Wellbeing. ITF House, London 2015.

41. Panganiban AU, Garcia OB. Contributory to stress and fatigue of Filipino seafarers. Asia Pac J Marit Educ. 2017; 3(1): 1-14.

42. McVeigh J, MacLachlan M. A silver wave? Filipino shipmates' experience of merchant seafaring. Marine Policy. 2019; 99: 283-297, doi: 10.1016/j.marpol.2018.10.012.

43. Jensen $\mathrm{HJ}$, Oldenburg M. Potentially traumatic experiences of seafarers. J Occup Med Toxicol. 2019; 14: 17, doi: 10.1186/s12995019-0238-9, indexed in Pubmed: 31164911.

44. Simon E, Fernandez K. The phenomenology of maritime piracy experiences of filipino seafarers. Psychological Studies. 2015; 61(1): 40-47, doi: 10.1007/s12646-015-0348-0.

45. Lefkowitz R, Slade MD. Seafarer mental health study. ITF House, London 2019.

46. Lefkowitz RY, Slade MD, Redlich CA. Rates and occupational characteristics of international seafarers with mental illness. Occup Med (Lond). 2019; 69(4): 279-282, doi: 10.1093/occmed/kqz069, indexed in Pubmed: 31094424.

47. Palmer T, Murray E. "Christ offered salvation, and not an easy life": How do port chaplains make sense of providing welfare for seafarers? An idiographic, phenomenological approach analysis. Int Marit Health. 2016; 67(2): 117-124, doi: 10.5603/IMH.2016.0022, indexed in Pubmed: 27364178. 
48. Pauksztat B, Grech M, Kitada M, et al. Seafarers' experiences during the COVID-19 pandemic: Report. 2020, doi: 10.21677/ wmu20201213.

49. Slišković A. Seafarers' well-being in the context of the CovID-19 pandemic: A qualitative study. Work. 2020; 67(4): 799-809, doi: 10.3233/WOR-203333, indexed in Pubmed: 33325430.

50. Stokes J, Arslan, V. (2020) Maritime Welfare Survey. Paper presented at World Maritime University's webinar entitled "Understanding the Effects of COVID19 on Seafarers" on 25 November 2020.
51. Hebbar AA, Mukesh N. COVID-19 and seafarers' rights to shore leave, repatriation and medical assistance: a pilot study. Int Marit Health. 2020; 71(4): 217-228, doi: 10.5603/IMH.2020.0040, indexed in Pubmed: 33394486.

52. Deacon BJ, McKay D. The biomedical model of psychological problems: A call for critical dialogue. Lancet. 2015; 16: 2-3.

53. Borrell-Carrió F, Suchman AL, Epstein RM. The biopsychosocial model 25 years later: principles, practice, and scientific inquiry. Ann Fam Med. 2004; 2(6): 576-582, doi: 10.1370/afm.245, indexed in Pubmed: 15576544. 